A list of Working Papers on the last pages

Forthcoming in:

Journal of Economic Behavior \& Organization, December 1989

No. 215,1988

EVOLUTION, ECONOMIC COMPETENCE, AND THE MARKET FOR CORPORATE CONTROL

by

Pavel Pelikan

Paper prepared for the IUI Conference on

Markets for Innovation, Ownership and Control,

June 12-16, 1988, at Grand Hotel, Saltsjöbaden

August, 1989 


\begin{abstract}
To assess the merits of the market for corporate control, this paper examines two processes which standard analysis does not study: the allocation of economic competence and the evolution of organizational structures. Economic competence is seen to be an unusual scarce resource embodied in the very ways in which individuals and organizations take economic decisions, which guides the allocation of all scarce resources, including itself. Its efficient allocation is shown to require an evolutionary trial-and-error process, where the market for corporate control plays a cructal role.
\end{abstract}





\title{
EVOLUTION, ECONOMIC COMPETENCE, AND THE MARKET FOR CORPORATE CONTROL
}

\author{
by \\ Pavel Pelikan* \\ The Industrial Institute for Economic and Social Research, \\ Box 5501, S-114 85 Stockholm, Sweden
}

\begin{abstract}
This paper shows how the market for corporate control contributes to the effective evolution of organizational structures by selecting for economic competence, thus contributing to dynamic social efficiency. To do so, the paper extends the evolutionary analyses of product markets by Alchian (1950) and Winter (1971).

The view that the market for corporate control is important for social efficiency was initially formulated by Marris (1963) and Manne (1965), and recently suported by Jensen (1988). The main argument is that this market disciplines and motivates managers to act in favor of stockholders under the threat of takeovers, or to force the incumbent management to leave, making room for managers who are better motivated to do so. In addition, Manne considers the market to be an important instrument for allowing more talented managers to replace the less talented ones.

This view has been criticized on both empirical and theoretical grounds - e.8., by Marris and Mueller (1980), Mueller (1986), and Scherer (1988). Empirically, the firms involved in takeovers are seen to compare poorly, in the long run, with industry averages. Although the occurence of highly
\end{abstract}


successful takeovers is recognized (cf. Scherer, p. 76), these are exceptions among a below-the-average majority. In hostile takeovers, a majority of the acquired firms are only mild underperformers, claimed not to justify the high costs and other disturbing effects which such takeovers imply.

The theoretical criticism falls into two categorles. The first assumes that capital markets are efficient, so that the market for corporate control is superfluous. If managertal performance is perfectly signalled by the value of stocks, and if the demand side on the market for managers consists of perfectly optimizing owners or boards of directors, efficiency in management of firms can indeed be achieved without any change in ultimate control. The second theoretical criticism claims on the contrary that the stock market is inefficient, which allows takeovers to be based on incorrect stock values, thus causing the market for corporate control to be soctally harmful.

The present argument opposes all of those criticisms. On the empirical side, the findings of the market's critics will be acknowledged, but shown of little relevance. In the evolutionary perspective of this paper, the few exceptional successes are substantially more important than the below-theaverage majority, and, moreover, the average itself depends on the presence or the absence of the market.

On the theoretical side, stock market inefficiency will be admitted, but not as evidence against the market for corporate control. It will on the contrary provide a major reason why social efficiency is better served with this market than without it. The market for managers together with the stock market as a signalling device are important, but insufficient to deal with an important social allocation problem, especially when their awn efficiency is uncertain. 
The extension of Alchian's and Vinter's evolutionary analyses is from product markets to markets for managers, capital, and corporate control. Moreover, non-market alternatives w1ll also be considered - such as Industrial policy or large-scale planning - to allow for comparative reasoning. The purpose is to avold what Demsetz (1969) calls intrvana fallacy' - that is, not to condemn a wasteful market if all its alternatives are even more wasteful. As no evolution can do without significant waste, to avold this fallacy is even more important in evolutionary analysis than in the standard static one."

A qualification of the present argument is in order. It is not necessarily the current form of the market for corporate control, nor the current game of mergers and takeovers, that I defend. I only argue that some market and some game of this kind are necessary for efficient allocation of scarce resources in society. Admitting that a specific form of this market, like that of any other market, may suffer from serious fallures, my argument is that policy should try to enhance this market by suitable institutional rules - e.g, along the lines mentioned by Shleifer and Vishny (1988) - and not hinder it, submit it to detailed case-to-case control, or eliminate it altoghether.

The paper is organized as follows. Section 1 defines economic competence (BC) and summarizes its most important properties. Section 2 draws a picture of a general economic organization. Section 3 considers EC as a property of both Individuals and organizations and examines the relationship between the two. A qualitative model of EC-allocation is outlined in section 4, and its evolutionary nature exposed in section 5 . Based on this model, section 6 explains why the market for corporate control is necessary for social efficiency. 


\section{Economic competence}

All agents, to be able to receive and use information, need some preexisting information telling them how to do so. While some of this information may consist of instructions received in the past, much of $1 t$ must initially reside with each agent, so that the first instructions can be understood, and the multi-stage process of recelving and using information can thus be started. To think of a computer which must initially be endowed with much information in its hardware to be able to receive programs and use data may be instructive. It is such agent-specific ("hardware") information that is referred to here by the term competence.

For economic analysis, a particularly important kind of competence is economic competence, defined as the competence to receive and use information for solving economic problems and taking economic decisions. EC thus refers to what is often called "optimization abilities" or "rationality". Three of its properties should be noted.

First, EC is an unusual kind of economic information. The economic information usually studied - such as data about prices, quantities, or qualities of goods - can be communicated, possibly at a cost, from one agent to another. In contrast, $\mathrm{EC}$ is a kind of information capital, inseparably tied to each economic agent, on which the very abilities of agents to communicate and use all ather economic information repose, but which cannot be directly communicated itself. It is thus tacit in the sense of Polanyi (1962). It is also difficult to observe and measure, even by its owners themselves, as the frequent cases of overestimation or underestimation of one's own competence amply illustrate. ${ }^{2}$

Although EC cannot be acquired by direct communication, an agent may Increase its stock by learning, possibly under the gutdance of a teacher. But learning requires some pre-existing competence as well. To be able to 
learn, an agent must inftially be endowed with a sophisticated plece of information in the form of a learning method, or, to include the interesting case of learning to learn studied by Stiglitz (1987), an even more sophisticated method for learning learning methods. All that an agent can potentially learn in an ideal learning environment is constrained by such inftially given learning (or meta-learning) competence ("talents").

Formally, the competence to learn more BC will also be counted as BC. It need not be exclusively specialized in learning only EC, but may in part correspond to general intelligence, allowing for learning other kinds of competence as well. Significant specialization seems nevertheless to take place. As the talents to become a top mustcian, a great chess master, a tennis champion, or a top mathematician do not seem to be highly correlated among themselves, there is no reason to expect that the talents for organizing and managing business operations and being rational in complex economic decisions are highly correlated with other talents either.

The recently developed theories of transaction casts, governance structures, principal-agent relationships, implicit contracts, optimal search, and job-assignment are, in fact, trying to identify and communicate some of the EC required for successful organtzing and managing of firms. But there is a substantial gap between these theories and the relevant EC. Although mastering these theories may help economists understand what goes on in the business world, this mastering is neither sufficient, nor necessary for becoming an excellent organizer, manager, or investor.

The second important property of $\mathrm{EC}$ is to be a determinant of economic behavior - meaning that EC is embodied in the very ways economic decisions are made. In other words, if these ways are expressed as decision functions, it is in these functions that EC is embodied. 
An 1mportant implication is that the neoclassical optimization postulate must be dropped - at least in its strong variant used in neoclassical welfare economics and neoclassical analysis of economic organizations. Instead, drawing on the ideas of Simon $(1955,1978)$ and Williamson (1975, 1985), a variant of bounded rationality must be admitted.

The reason why the optimization postulate must be dropped is worth noting. With this postulate, the only determinants of agents' behaviors can be their objective functions (or sets of preferences), which are assumed always to be maximized. To admit that also EC determines economic behavior means to admit that agents may also differ in their abilities to pursue objectives. Two agents with the same objective function in the same situation may thus take systematically different decisions, if endowed with different EC. This property exposes the important possibility that even the most disciplined agent, motivated by optimal incentives, may become a source of important social losses, if his EC is inadequate to the decision task to which he is assigned. $\Rightarrow$ ?

The third important property of EC is to be a scarce resource, whose allocation may be crucial for the efficiency of economic organizations, Including entire economies. It is this property that makes EC different from bounded rationality. The latter is seen by both Simon and Williamson to be a general phenomenon which affects all agents in about the same way. In contrast, EC is an agent-specific resource, whose stocks may differ from one agent to another, implying that the rationality of different agents may be bounded in different ways and degrees.

Rather than maximizing EC for each decision task, the basic principle of efficlent EC-allocation is to match the EC of agents with the kind and the difficulty of the decision tasks they have to perform. The term 'competence-difficulty gaps' due to Heiner (1983) is a good way to express 
this situation. Clearly, it is such gaps, and more precisely the losses they imply, that should be minimized: highly difficult decision tasks of great impact on final outcomes should be assigned only to highly competent agents and, symmetrically, decision tasks should not be made more difficult than the agents available can handle without excessively costly errors.

If the EC of different agents suits decision tasks of different kinds and difficulties, it is a heterogenous resource. In spite of this complication, its allocation may at first seem easy to handle by standard economic analysis extended to include economic information and human capital. What makes the problem of EC-allocation look so easy is that EC seems to be a simple combination of the two: it is a kind of economic information and its most unpleasant properties - to be heterogenous, impossible to communicate, and difficult to observe and measure - are the same as those of human capital. Yet a closer examination reveals that the combination is far from simple. The stumbling-block is that each of the two has been studied precisely under the assumption that it does not have an essential property of the other: the economic information studied must be communicable, whereas human capital may concern all possible skills, but not those of economic decision-making.

Why neoclassical theory of human capital cannot deal with these skills is instructive to note. To recall, this theory is about investment in costly education, by which a person, postulated to be a perfect economic optimizer, is to improve her skills, thereby increasing her value as a factor of production. The important, but rarely noted point is that if these skills were to be of the EC kind, needed for optimal investing itself, the optimization postulate would be contradicted and a paradox would result. To see this, imagine a poorly competent investor who is to optimize his investment in studies of the economics of investment. His problem is on a 
par with Catch 22: he cannot optimize, with all the necessary data about the costs and the future beneflts of such studies avallable, before having invested much - and possibly too much! - in them.4

What constitutes an even more serlous paradox for neoclassical analysis is the problem of EC-allocation involving several economic agents. The second and third properties of EC - to be a determinant of economic behavior and a scarce resource - are mutually incompatible within the neoclassical framework. They imply that $E C$ is an element of the economic calculus by which scarce resources are allocated, and at the same time one of the resources which are being allocated. In other words, it is by means of EC that EC is allocated. EC is thus to play two roles which the axiomatic building of neoclassical welfare economics needs to keep separated - to be a tool as well as an object of the social allocation process. The resource-allocation mechanism which runs this process can thus no longer be seen as an imperturbable device, elevated above the problem of scarcity, but its own parts must now be recognized as possibly scarce. Much like an organism rather than mechanism, it must then also assume the task of allocating these parts, and thus keep building and rebuilding itself.s:

All of this is central to the point at issue. Consider the argument that the market for managers, together with learning (adaptation) within firms, suffices to provide for competently managed firms, thus making the market for corporate control superfluous. To be sure, these are two important ways to improve the $\mathrm{EC}$ of the management of firms, but they cannot solve this problem entirely, unless certain other EC has already been efficiently allocated. In part, this is the EC of the actual managers, including their learning potential, by which all learning within firms can strongly be constrained. And in part this is the EC of the buyers on the 
market for managers - owners in person, or represented by board of directors - by which the efflclency of this market stands or falls.

An important part of the EC-allocation problem thus remains unsolved the one of efficient allocation of EC to the board of directors, and ultimately to the owners. That alse the ownership of firms calls for allocation of adequate $B C$ is a key part of the present argument. If the society contained potential owners of more sultable EC than the actual ones, social efficiency would require a reallocation of the ownership of firms from the latter to the former. The obvious reason is that these are likely to choose more competent board of directors, who are likely to appoint more competent managers, who in turn are likely to enable the firms to adapt better to whatever social and private demands there are to be met.

A major difficulty with EC-allocation is that it seems to lead to an infinite regress. The problem of how to allocate suitable EC to the ownership of firms raises the problem of which EC should guide this allocation. Should it be the EC of some superowners, shopping on a market for owners? Or should it rather be the EC of government, appointing the boards of directors or, more directly, the managers? Whatever the answer, the problem of which EC should guide the allocation of this EC would immediately arise, and so on.

Neoclassical analysis is saved from this paradox by the optimization postulate. This postulate assumes, in essence, that at least some of the EC involved is abundant, thus fixing an artificial but convenient starting point from which the rest of resource allocation can straightforwardly unfold. Most often, it is the EC of the managers which is implicitly assumed abundant. Provided their incentives are right, the managers are assumed to hire the best labor available, solve optimally the problems of job design and assignment, and in general maximize the firm's profits. If, 
as some recent theorles do, this EC is recognized as scarce, by admitting that different managers may be of different talents, then it is the EC of the owners who shop on the market for managers, and of the investors who trade on the stock market that is assumed abundant.

Now the question is: "How can we understand the social allocation problem, if no one's EC is above suspicion?"

\section{General economic organizations}

The first prerequisite for an answer is a clear picture of an economic organization. For the present purposes, the following one seems to be the simplest.

Consider an economic organization - e.g., a firm, a government agency, or an entire economy - coordinating the activities of a set of economic agents. The agents can be individuals, or smaller organizations. In the latter case, the same picture can be made, mutatis mutandis, of each such agent.

Both agents and organizations are characterlzed by their economic behavior - e.g., as described by a decision (or response) function. To recall, such behavior has been assumed to have two determinants: (1) the set of preferences (objective function) which the agent or the organization pursues, or can be assumed to pursue; and (2) the EC with which this pursuit is conducted.

An organization is moreover characterized by three other terms: 'arrangement', 'structure', and 'regime'. As all of them have been used in many different ways, care is necessary in specifying what they mean here.

'Arrangement' is defined as the set of economic decision tasks within an organization, and the ways in which they are linked together. Examples are a market, with decision tasks for buyers and sellers, and possibly also 
an auctioneer, or a (planning) hlerarchy, with dectsion tasks for a manager (planner) and a number of subordinate producers and consumers.

'Structure' (S) is defined as the arrangement and the agents which actually assume the tasks, together. Since it is the agents' behaviors, as coordinated by the arrangement, that produce the global behavior of the organization, this definition makes true the proposition that structure determines behavior and performace. $S$ thus corresponds to what is often called 'resource-allocation mechanism'.

As the term 'structure' has often been used for what is called here 'arrangement', while what is called here 'structure' has often been identified with the organization itself, it is important to realize the differences. In the present terminology, 'structure' is 'arrangement plus agents', and an organization is something more stable than a structure. An organization must be able to change its structure - e.g., by exit or entry of agents, or by changes in its arrangement - without losing its identity. Clearly, one could not study the evolution of structures in organizations, if the two were defined to mean the same thing.

Adapting a definition by Hurwicz (1971), the 'regime' (R) of an organization is interpreted as the set of its institutional rules which constrain the behavior of its agents, much like the rules of a game constrain the behavior of its players. Examples of such rules are property rights, signalling rules, labor law, corporation law, and antitrust law.6s

Note that regimes can be used to characterize different types of economies. For example, a capitalist economy can be characterized by an $R$ which allows for private ownership of capital, transferrable through capital markets. In contrast, all definitions of socialism imply institutional rules that prohibit, or at least significantly limit, this kind of ownership and market, even if labor and product markets may be allowed. 
As long as structures are constant, not much attention need be paid to regimes. Since for each agent, the institutional rules to be respected are implicit in his decision task, and since the decision tasks within an organization are determined by its arrangement, the arrangement and the structure thus automatically include the prevalling $R$. For instance, this can be seen as the reason why neoclassical analysis usually describes a capitalist economy as a set of markets, and a socialist economy as a hlerarchy of planning - that is, refers to their respective arrangements while leaving only implicit the property rights and signalling rules of the corresponding regimes.

It is when changes of arrangements and structures are to be studied that regimes become important. Since what varies can be studied only with reference to something else which does not, the first question is, then, what invariant can characterize an organization instead of the now variable S. As $S$ can often evolve while the prevaling institutional rules remain the same, $R$ is the natural condidate for this role - at least untill its own evolution is to be studied. One may think of the rules of a game which may remain the same, while players may enter or exit, form or dissolve coalitions, or otherwise change their roles and mutual relations within the game. What makes $R$ particularly important is that it is largely responsible for how the $S$ under its rules will evolve.7?

In the present argument it is the $R$ of the economy considered that will be of particular importance. The central question can now be formulated as follows: "Is it necessary, for an economy to be efficient, that its $R$ allows for the market for corporate control?"

\section{The economic competence of arganizations}

Much like other scarce resources, BC can belong to individuals and to 
organizations. But whereas the holding of an organization in other resources can usually be counted as a simple sum of the holdings of its members, for EC the relationship between the two is more complex.

As EC corresponds to the abilities to pursue objectives, the $\mathrm{EC}$ of an organization corresponds to what is usually called "efficiency" - such as the allocative efficiency of an economy, meaning the economy's abilities to maximize a Pareto welfare function, or the x-efficiency of a firm, meaning the firm's abilities to maximize profits. As the EC of an individual was noted to correspond to 'rationality', rationality and efficiency are thus provided with an important common denominator - to be equivalent to the EC of their respective owners. The question of how the $E C$ of organizations depends on the EC of their members is then the question of how organizational efficiency depends on individual rationality.

As noted in section 1, EC is a determinant of economic behavior, which, for an organization, is also determined by the organization's structure, as follows from the present definition of $S$. Thus, the EC of an organization is embodied in its $S$. But $S$ consists of a set of member-agents and the arrangement which determines and interconnects their decision tasks. This means that the EC of an organization may come from two sources: the individual EC of the agents, and the arrangement. If the agents with their EC are given, it is by arranging them into a certain structure that the EC of the organization is produced.

The analogy with computer hardware may again be helpful. Much like the hardware embodies the competence of an computer to use software, the structure embodies the competence of an organization to use other economic information and take economic decisions; and much like the hardware must be produced by wiring together components of certain functional abilities, the structure must be produced by arranging agents of certain individual EC. 
Of course, there are also important differences. One appears when we ask whe does the arranging or wiring: whereas the wiring of a computer must be done by an exogenous constructor, most of the arranging of an economic organization must be done endogenously by the member-agents themselves. But regardless of how the result is obtained, the fact that it dependens on both the agents ("components") and the1r arrangement ("wiring") remains.8

The contributions of the two sources of organizational EC can be clarified by two elementary implications: (1) the same agents can form different structures, if put into different arrangements; and (2) the same arrangement can result in different structures, if filled up with different, or differently permuted, agents. The organization's EC will change in either case. The lattter points to an important unrecognized problem. As long as all economic agents are assumed to have the same decision-making abilities, no gains can be seen in replacing them or permuting them within an organization. The present approach can thus explain some important facts well-known in practice, which neither neoclassical economics nor the usual theories of bounded rationality can: that just a few personnel changes may significantly affect the efficiency of an entire organization, and that the efficiency of a successful organization cannot be transmitted to another organization, even if the successful arrangement were copied to the smallest detail.

Because of the optimization postulate, neoclassical economics suffers from another limitation which is instructive to note. This is to study organizations where individual EC (rationality) is always abundant, while only their global BC (efficiency) may be scarce. For national economies, this directly follows from the central theoren of neoclassical welfare economics, which shows that only some economies under some conditions are 
allocatively efficient. To admit that economies may suffer from more or less serious market and/or government fallures is indeed to admit that, because of a deficient arrangement, their global EC may be inadequate to the social allocation problem they are to solve. This 1s, then, also to admit that, in spite of abundant individual $\mathrm{EC}$, the adequate global EC is scarce.

The case of firms is interesting for its ambivalence. In traditional welfare economics, firms are monolithic agents, which the optinization postulate assumes to be perfect profit-maximizers - that is, of abundant EC. In more recent studies - e.g., as surveyed by Radner (1986) - where firms are examined as multipersonal organizations per se, and not as agents of an economy, the optimization postulate is no longer applied to them, but to their individual members instead.

That neoclassical economics deals only with a special kind of organizations becomes particularly clear when we recall weberian bureaucracles, assumed to have precisely the opposite properties - highly competent organizations whose ingenious arrangement more than compensates for limitations of individual bureaucrats. One consequence is that neoclassical analysis cannot properly study multilevel organizations, including the typical national economy containing multipersonal firms. Clearly, if organizations of one level may have to serve as agents in organizations of a higher level, organizations with limited EC cannot qualify, if the EC of the agents is postulated abundant. If Simon (1969) is right that the human brain can understand complexity only be decomposing it into several levels of relative simplicity, this would mean that complexity cannot be understood by neoclassical means.

In contrast, to admit scarcity of both individual and organizational EC leads to a general view of economic organizations, where neoclassical 
organizations as well as weberian bureaucarcles are included as special cases, while the study of multilevel organizations is made possible. The relationship between two neighboring levels of EC can then be viewed as that of production, in which the BC of an organization is produced from the EC of its member-agents.

\section{Allocation of economic competence: outline of a model}

The purpose of the above explanations was to expose as clearly as possible the following principle: allocating $E C$ means arranging agents: $E C$ into the structures of organizations, and thus producing organizational EC.

This means that allocation of EC can be anatomized into the same basic processes by which structures form and reform, which may be described as designing, assigning, and interconnecting of economic decision tasks.

Evolutionary economics aside, the nearest relatives of the present problem in the literature are the job-assignment problem surveyed and elaborated by Waldman (1984) and the problem of self-perpetuation of organizations briefly outlined by Stiglitz (1984).93 Neither, however, embraces the problem of EC-allocation in its entirety, and it is instructive to note why.

The job-assignment problem has been studied under the assumption that all jobs have already been designed and interconnected - that is, that the organization's arrangement is a priori given - leaving open only the question of their assignment to speciflc agents. Moreover, the key job of assigning all the other fobs is assumed already assigned, and to a perfectly competent optimizer on the top of everything else - thus violating the present requirement that no one's EC be above suspicion.

The self-perpetuation problem is limited to agents choosing their successors for the same decision tasks within an organization. Here, in 
contrast, the tasks need not remain the same, but may also be created, modifled, or abolished. Moreover, agents may enter, exit, or move among the tasks, in quite a general manner. The present problem is thus not only that of how organizations self-perpetuate, but also that of how they selforganize and evolve.10s

A more useful reference is the problem studied by Lucas (1978). Assuming that managerial talents are scarce and unequally distributed, and that the output of a firm depends on its size and on the talent of its manager, the problem is to find the optimum number and size distribution of firms which maximize the total output, given the distribution of managerial talents in society. This is a clearly stated special case of the present problem: how to organize an optimal structure of production, given the distribution of individual EC in society.

It is convenient indeed to limit the problem of EC-allocation to production. Its study can then be relatively value-free, largely avoiding the thorny issues of consumer sovereignty and social values in general. Whatever individual and social values there might be, and whatever private and social final demands they might Imply, misallocation of EC within production - such as management of firms assigned to persons of poor managerial talents - is always socially wasteful.

In contrast to Lucas, the focus is here not on what an optimal structure of production 1s, but on the process by which such a structure would form and evolve - that is, by which firms of suitable sizes would be formed, and the managers of suitable talents would be found, selected, and matched with appropriate firms. Clearly, such a process calls for decisions and actions also of other kinds of agents than managers - such as directors and owners - for which other kinds of EC may be demanded such as the EC to assess the managers' $\mathrm{EC}$. Consequently, the $S$ considered 
here must be more complex than the one considered by Lucas, which already is more complex than the usually studied one-level structures. Without saylng is explicitly, Lucas considers two levels, containing markets for labor, physical capital, and products among firms, and simple "one managerhomogenous labor" hierarchies within firms.

Here, in addition, the inter-firm level must involve markets for managers, financial capital, and control over firms. Moreover, to allow for comparative reasoning, their non-market supplements or alternatives must also be considered - such as industrial policy or planning, government allocation of capital, or government awnership of firms and appointment of managers. Some government policy-making or planning agencies must then also enter the picture, constituting another kind of economic organizations which must select their members from the same set of given individuals as the firms.

At the intra-firm level, it is essential that the internal bierarchies of firms include the sources of ultimate control - such as the boards of directors which appoint and control the managers and/or the ultimate owners who select the boards, or, alternatively, who directly appoint and control the managers. Of particular importance for the present argument is the process by which the owners are selected. Moreover, the internal hierarchies of government agencies and government-owned firms must be deplcted in a comparable way, tracing the ultimate control over them through public officials to the politiclans selected by the prevailing political system.

Now, the important question is, how to incorporate EC-allocation while continuing to explain the allocation of other scarce resources. A simple way, sufficient for the present purposes, is to regard the two kinds of allocation as taking turns in a sequential process, alternating two kinds of 
periods, say $A$ and $B$. Let the traditional allocation - 1.e., the traditional kinds of signalling, production, and trade - take place during the Aperiods, conducted by a temporarily fixed $S$, embodying a certain temporarily fixed EC. EC-allocation then takes place during the B-pertods, making $S$ change (evolve, self-organize), and thus prepare for the next Aperiod.

It is during the B-periods that decision tasks are designed, assigned, and interconnected. This is how markets and hierarchies may form, grow, reorganize, merge, split, contract, or dissolve, and, within them, individuals may enter or exit, move from one decision task to another, or modify the tasks. During these changes, individuals may also improve their short-term EC under the constraint of their long-term (learning) EC." '

In sum, the resource-allocation during an $\mathrm{A}$-period is conducted by the $S$ which has resulted from the preceding B-period. The efficiency of the allocation of all other scarce resources thus depends on the efficiency of the previous allocation of $\mathrm{EC}$, as embodied in the prevailing $S$. On the other hand, the changes of $S$, and the corresponding allocation of EC which can take place during a B-period, are constrained by the allocative result of the preceding A-period. For example, a firm can be formed or expanded only within the limits of available financial capital, and must close if these limits become too narrow.

In order to model changes of $S$ in clear terms of methodological individualism (and thus avold the confusion of holistic mysteries), it is necessary to enlarge the usual view of microeconomic behavior by a new dimension. The processes of designing, assigning, and interconnecting of economic decision tasks must be depicted in sufficient detail to make clear how they can result from specific actions of speciftc individuals. 
Under a capitalist $R$ in the short run, most of these actions may appear as ordinary transactions on certain markets - in particular the markets for labor, including management, and for capital, including corporate control which may, like any other markets, have their supply, demand, and equiltbirum prices. In the long run, however, these actions differ from other market transactions in two important aspects. First, they are the elements of which the economy's $S$ is built and rebuilt, with lasting consequences on how efficient, or inefficient, the subsequent resourceallocation will be. Second, they may be influenced by preferences and constraints of other kinds than the usually considered ones.

Terming this dimension of microeconomic behavior, and the corresponding actions, preferences, and constraints, as assoctative, let me exemplify them as follows. Associative actions include the explicit and implicit contracting between capital owners, managers, and other employees, forming the structure of a firm; associative constraints include limited spans of control and limited precision of languages which limit the size of efficient hierarchies; examples of associative preferences are empirebuilding passions, nepotism, and other likes and dislikes for decision tasks as such, and/or for persons as partners, superiors, or subordinates.

To be sure, associative actions are also subject to the familiar resource constraints and guided by the famfliar preferences over eventual allocative outcomes. But the influence of associative constraints and preferences may sometimes prevail, and thus constitute another important reason than inadequate individual $\mathrm{BC}$, for which a firm or en entire economy may evolve an economically incompetent, i.e. allocatively inefficient, $S$.

\section{Comparative evolutionary economics}

An important implication of the previous section is that BC-allocation must 
be conducted by means of changes of $S$, which makes it equivalent to $S$ evolution. To understand the meaning of this equivalence, recall the difference between $B C$ and other economic information. As opposed to the latter, which can be communicated from one part of $S$ to another, EC, which is by definition tacit, and thus bound to structures and their parts, can be allocated only by moving and rearranging the parts thenselves.

To see the evolutionary role of the market for corporate control, it is now necessary to clarify how $S$-evolution is influenced by the prevailing $R$, and what difference it makes whether the $R$ allows for that market or not.

In the above picture of EC-allocation, the influence of $\mathrm{R}$ falls into two parts. During A-periods, the influence is indirect, via the regime's rules governing the traditional resource-allocation - such as legal conditions of signalling and trade on existing product markets, or within existing hlerarchies - the results of which determine, for the following B-periods, which changes of $S$ become economically feasible. During $B$-periods, the influence is direct, via those rules that are specialized in governing associative actions - such as legal conditions of entry, exit, takeovers, and organizational and personal changes within firms and agencies - which determine which of the economically feasible changes are also institutionally permissible.

With the exception of Commons (1929), economic theory has left the Influence of $R$ on S-evolution largely unexplored, although Alchian (1950) and Winter (1971) can be said to study a special case of 1t. In the present terms, what they do is to study the $S$ of a product market under $a$ standard capitalist $R$. Initially, the $S$ contains a set of firms with different EC for profit-maximizing. Their main question is, whether or not market selection will eliminate the firms with inadequate $E C$, and thus make 
the $S$ evolve towards a state where only the BC capable of profit-maximizing is allocated to the control over production.

To generalize this case, consider the well-known flaws of product market selection: to be slow and costly, by requiring too many trials of which most will become fallures, and by allowing a large firm to lose much of 1 ts previous EC and yet survive for a long time, while a small firm of much higher EC may be eliminated by pure accident. A seemingly easy remedy is to accelerate the elimination of eventual losers and to support the future winners by providing them with more financial capital. Upon a closer view, however, this remedy proves far from easy. The reason is that it requires much of suitable EC - the one for early recognition of future profit-maximizers - if the product market selection is to be made faster and cheaper, rather than even slower and costlier. That also this EC is scarce has been amply fllustrated by the recent experience with industrial policy, when many governments intended to pick and support winners, while more often than not they bailed out losers instead.'2) And private capital owners do not always succeed at this task, either. Of those who try only some do, while others lose large sums or go bankrupt. The general problem of EC-allocation and the corresponding S-evolution must thus concern also other kinds of EC than that for profit-maximizing in production.

To state this problem, consider a given society as a collection of individuals endowed with different EC. The central question is: Under what $R$ would they most likely evolve an efficient $S$ of production, which would allow them to make an efflcient use of all their scarce resources, including their scarce EC, for meeting their final individual and collective demands. whatever these might be? In contrast to Lucas (1978) and Williamson (1975, 1985), who regard the $S$ of production as an exogenous variable, trying to determine 1ts optimal state themselves, $S$ is here an endogenous variable, to 
be formed and provided with the best attainable EC during an endogenous evolutionary process. It is this process, and the influence that the prevailing $R$ exerts on $1 t$, that is here in focus.

According to the present argument, an efficient $S$ of production cannot even be determined by theory. Although the usually considered technological factors and transaction costs remain important, they do not suffice to determine an efficient $S$. This also depends on the available EC, which, because of its tacitness, no theory can fully take into conslderation. For example, it is well known that transactions costs are difficult to measure with enough precision, and arrangements which save on them are difficult to design in all relevant details. Much will therefore depend on the EC at work, with which the general principles of transaction costs economics will be used in particular circumstance - e.g., in recognizing and avoiding oversized firms and exaggerated centralization, in designing effective contracts, and - perhaps above all - in assigning the most important tasks to persons with the most suitable EC, or at least in keeping these tasks away from persons with inadequate EC. The presence or absence of a few exceptionally talented entrepreneurs, which cannot a priori be measured, can thus be decisive for how concentrated an efficlent $S$ should be.

It would be convenient to have a kind of efficiency for assessing different R's, analogous to allocative (Pareto) efflclency used for assessing different S's. In a slightly different context, Marris and Mueller (1980) speak of "adaptive efficlency", and Eliasson (1985) of "Schumpeter efflciency". As the former term sounds too passive, as if $S$ should only adapt to exogenous changes, I opt for the latter, redefining it within the present $R-S$ framework in Pelikan (1988). Roughly, an $R$ is said to be Schumpeter efficient, if it can guide S-evolution towards the allocatively "least inefficlenct" $S$, under the constraint of the available individual EC. 
Just as a typical $S$ is Pareto inefficient, suffering from various allocative fallures, a typical $R$ is Schumpeter inefficient, suffering from various Schumpeterian (S-evolutionary) fallures. A realistic task of comparing different regimes is then to find an $R$ whose Schumpeterian fallures are relatively least costly to society.

The issue of large-scale planning, as debated in the so-called Great Socialist Controversy, is of particular importance for the present argument. To recall, two main answers have competed with each other. One argues that, as opposed to markets, no large-scale planning can ever be efficient, because of various informational and motivational obstacles. The second answer formally proves, under standard neoclassical assumptions, that such obstacles can be overcome and that large-scale planning can be allocatively efficient under less restrictive conditions than its market alternatives. ${ }^{\text {a.s }}$

The present argument opposes both these answers, suggesting a third one. The first answer is opposed for the simple empirical reason that successful large-scale planning does exist in large capitalist firms, some even larger and not much less diversified than some small socialist economies. These firms are thus the living proofs that - whether neoclassical theory is right or wrong - all the informational and motivational obstacles can reasonably be overcome in practice, and that even a very large centrally planned organization can be made reasonably efficient.

The second answer is opposed because it reposes on the optimization postulate, thus limiting the issue to the allocation of all other scarce resources, but not EC. Indeed, the suggested planning arrangements can be efficient only if the EC of all firms and the Planning Agency is heroically assumed abundant. That is, these firms and agencies must be able to opt1mize in all the tasks, however sophisticated, which such an arrangement 
may assign to them. This means, among other things, that all firms must be of the right sizes, efficiently organized, and competently managed. In contrast, the present argument points out, corroborated by ample empirical evidence from the USSR and Eastern Europe, that it is precisely the scarcity of such firms that may be the decisive obstacle to the success of any socialist economic reform. ${ }^{14}$

The difficulties of large-scale planning with EC-allocation stem from the fact that no one's EC is above suspicion. This prevents EC from becoming the subject of any a priorl established optimal planning. Instead, the allocation problem must include the fundamental questions of who is to manage, and who is to plan. Any initially established planning $S$ is likely to be far from embodying an efficient allocation of $\mathrm{EC}$ in the design of its tasks as well as in their assignment to specific individuals. The economy may contain more talented managers and/or planners than some of the initially appointed ones. Some firms may be wrongly dimensioned and/or wrongly organized. Social efficiency then requires an allocation process by which the more talented individuals can replace the less talented ones, and the errors in the sizes and structures of firms can be corrected. And if one were tempted to think of some "superplanners" to plan this process, their EC would also have to be put in question, and the design as well as the assignment of their tasks again included in the allocation problem.

The third answer thus emerges. Efflcienct large-scale planning can exist, but only if conducted with adequate $\mathrm{EC}$. As this EC is scarce - the larger the scale of planning, the scarcer the EC becomes - and, as it is by definition tacit and difficult to measure, scarce EC is also needed to measure and allocate this EC. Hence, effictent large-scale planning can exist, but cannot be obtained by large-scale planning. Whatever large-scale planning may be needed in an optinal $S$ of production, it can be obtained 
only through an evolution with many trials, where markets must have the last word.

Successful large firms, which are so easily taken for granted in a static view of advanced capitalist economies, must thus be regarded as rare successes of a broad evolutionary process, where they constitute only a tiny visible minority among all the unsuccessful and no longer visible trials. Boisy and costly experimentation is the only means to insure that large-scale planning will evolve the EC adequate for its scale, or adjust its scale to the EC available. Vithout many trials, such planning would unlikely be found, and without the selective pressure of competitive markets, it would likely grow inefficient. It is, then, the much lower variety of trials and the absence of market selection that constitute the main reason why large-scale planning is so unlikely to succeed in politicoadministratively formed government agencies - in spite of its empirically documented success in market-evolved, possibly even larger capitalist firms.

This is, however, not to exclude large-scale planning from also actively contributing to an efficient S-evolution. Many large efficient firms may also become efficient in planning their further expansion or reorganization. The point is, however, that such efficient planning can emerge only gradually, as a result of exceptionally successful trials, at a later stage of S-evolution. It cannot be assumed to exist from the beginning, nor trusted to the end. No planning is above suspicion of itself being, or becoming, a costly organizational error which should be dissolved into a set of markets, or replaced by a different planning, conducted by different persons. Inefficient planning which is allowed to survive and plan its further expansion is a particularly harmful case of a cumulative, pathdependent evolutionary process, which may cause the entire structure of production to evolve towards increasing inefficiency. 


\section{Evolutionary reasons for the market for corporate control}

That organizational trials and errors as well as competitive markets are needed for efficient S-evolution gives a rough but useful clue as to what $R$ may minimize Schumpeterian failures. Such $R$ should not prevent promising trials, nor perpetuate committed errors (cf. Pelikan 1985, 1988). Also, it should allow all the needed markets to form, develop, and preserve a minimum degree of competitiveness. Now the remaining question is whether the needed markets include the market for corporate control.

As the EC embodied in the $S$ of production can sometimes be improved by having some firms merge into larger units, or divide into smaller ones, or have their ultimate control transferred to other owners, social efficiency requires some institutionally defined means to allow for such changes. And if no one's EC is above suspicion, then no a priori appointed planners, nor the incumbent managers, directors, or capital owners can be expected always to have the most suitable EC for deciding on such changes. Consequently, by simple elimination, a competitive market for the ultimate control over firms appears to be the only alternative.

Another interpretation of the empirical evidence submitted by the market's critics thus emerges. From the present evolutionary perspective, neither costly errors nor poor statistical averages need be of much significance. Thinking of the vast majority of unsuccessful mutations, it is difficult to imagine a noisler and more wasteful process than biological evolution, and yet this may be the only way to increasingly complex forms of life. The noise and waste of an evolutionary process may well be the necessary price to pay for the formation of increasingly competent economic structures as well. In the long run, the losses caused by the majority of erroneous trials may be more than outweighed by the gains of slowly accumulating exceptional successes - provided the errors are promptly 
eliminated and the successes preserved. Ultimately, an optimal $\mathrm{S}$ will be constituted only of such exceptional and thus a priord unlikely successes.

Of course, the question of how prompt the elimination of errors should be is a delicate one. While it may be felt that the average of 10 years needed to redress or close a mismanaged U.S. firm is too high (cf. Scherer), if comparison were made with non-capitalist economies - where the corresponding delays must be measured in decades, if not centuries - this average must be considered satisfactory.

Recall also the evidence that in the long run, most of the firms involved in takeovers are below the industry's average in profitability as well as in the growth of the value of shares. In addition to the limited relevance of falled trials, even if they are in majority, there is another reason why this is no evidence against the market for corporate control. The average itself depends on the presence or absence of the market. If there is a race, everyone will run faster, and thus raise the average speed, in comparison with a quiet walk without racing. Relevant evidence could be obtained only by comparing the effects of the possibility of takeovers on all firms, be they actually involved in a takeover or not, and make a comparison with the firms in an initially similar economy where takeovers have been prohibited.

The impossibility to measure EC directly and reliably, which Marris and Mueller (1980) use as the reason to dismiss the entire competence argument, is here an important evidence for it. If such measuring were possible, neoclassical optimal planning could also be used for EC-allocation. What makes competitive markets irreplaceable is precisely the fact that EC can be measured oniy indirectly, by means of competition comparing its eventual performance in the relevant field, or subjectively, by guesses of some other EC - such as the EC of capital owners. But then another competitive market 
- such as a capttal market - is again necessary, to compare the performance of that EC in the field of relevant guessing.

To see why, consider how the competence for playing a game can be measured. Good subjective guesses require much competence for judging both the game and the players; more objective results can only be obtained from tournaments in that game. If the relevant field is the control over firms, the tournament can hardly be anything else than a competitive market for this control. To expect the best relevant EC to be found by the politicoadministrative competition within government would be like expecting tennis tournaments to find out the best chess players (or vice versa).

To test the present argument, consider the following objections to the market for corporate control: (1) poorly managed firms can be improved by better incentives for incumbent managers, in particular by allowing them to own larger amounts of shares; (2) the incumbent managers may have to be replaced, but the market for managers, and the stock market as an indicator of managerial performance, suffice to solve the problem; (3) far from being efficient, the stock market may err no less than the managers, causing the market for corporate contral to err as well (cf. Scherer).

The suggested answers are as follows. (1) Better incentives for managers can often help, but cannot solve the entire problem. Even the best motivated managers may cause serfous losses to others and to themselves, if their $\mathrm{EC}$ is inadequate. It is not even sufficient to motivate them to act accordingly to the limits of their EC, as some ingenious bargaining schemes have suggested. To know such limits requires another kind of $\mathrm{EC}$ which may be just as scarce; many incompetent persons seem also to lack the competence to know how incompetent they are.

(2) To serve as an indicator of managers' performance and to allow shareholders to vote with their feet are two important functions of the 
stock market, but again insufficlent by themselves. If the ultimate control over firms cannot be traded - e.g., if ownershlp of shares is separated from voting rights - a serious misallocations of EC could be perpetuated, or its correction made extremely costly. To be sure, competent shareholders can recognize and leave the firms whose managers and boards of directors happen to be of inadequate EC. But this has little effect on EC-allocation itself. The managers and directors can either stay put, especially if they can obtain government subsidies, or lose their control only slowly, at the end of a complete bankrupcy process. In such a case, to change the allocation of EC to the control over production requires to start a different firm with different managers, directors, and owners. Clearly, as a way of improving EC-allocation, such a complete-bankrupcynew-start method is extremely slow and costly. And although it may sometimes be useful as a last resort, trading in control over still viable firms is often a faster and soclally cheaper alternative.

In contrast to Scherer's views, the takeovers of only mild underperformers can thus be a sign of Schumpeterian efficiency: to respond to small deviations usually provides for smoother and cheaper adjustments than to wait for large deviations; moreover, this also suggests that high EC which can recognize and respond to such small deviations is already at work on the market for corporate control - even if theoretical economists may not always fully appreclate its contents and signiflcance.

(3) As no one's EC is here above suspicion, it is of course admitted that capital owners trading on the stock market may lack adequate EC, and thus cause this market to be inefficient. But this is precisely an important reason why the market for corporate control should be defended. That standard analysis may arrive at the opposite conlusion is due to its simplified view of the social role of markets. It views a market only as a 
given allocation device which is to allocate scarce resources by means of given EC. If this EC is inadequate, the market is inefficient and its social value is put in doubt. Here, in contrast, a market is above all an evolutionary device which is to improve the EC for the allocation of other scarce resources.

The market for corporate control would indeed be superfluous if only managers, but not owners, had inadequate EC. In that case, no changes in the ultimate control over firms would ever be needed, and the market for managers, together with the stock market as a pure indicator of managers' performance, would suffice. Because this is not the case, the market for corporate control is irreplaceable. The feat of this mariset is to connect two crucial kinds of EC-allocation into one closed circle by providing for a double selection of both managers and owners. This is indeed the only known way for EC-allocation to be saved from infinite regress, if no one's EC is above suspicion: it is the capital owners who more or less directly select the managers, and it is the performance of the selected managers by which the owners stand or fall.

As an example, consider the often discussed problem of short-sighted managers. While such managers may exist, succeed for a while, and cause serious social losses, they must now be considered fointly with the capital owners who appoint them and/or invest in them. If correctly formulated final demands provide the ultimate criteria for judging the abilities of producers (and if not, the fault is not with the market for corporate contral!), the firms under such managers must in the long run decrease in value, thus undermining the position of their owners as well. And while such unions of short-sighted managers and owners might also be demoted by pure product market selection, without the market for corporate control, this would take even more time and require the sacrifice of entire firms. 
A great merit of the market for corporate control is that short-sighted managers and owners may be forced to go while their firms may still be saved. Although the process may still be unpleasantly slow and notsy, if no deus ex machina can be called upon - and, as shown above, government is among the least promising candidates for this role - the problem of shortsightedness in the organization and management of production has no superior solution.

Finally, the present argument should also be tested vis-a-vis the threats of market fallures. Such fallures may call for modifications of the institutional rules by which the market for corporate control is shaped, but without weakening the argument for its existence. The usual sources of allocative failures - such as asymmetric information and incentive incompatibility - do not seem to imply any significant comparative disadvantage for the market for corporate control, for all its non-market alternatives appear prone to them at least as much.

Let me therefore focus on two Schumpeterian failures, specific to Sevolution. One is the possibility of premature elimination of good learners. Because all learning requires time, selection may work too fast, allowing some excellent learners to be eliminated by mediocre learners who have only temporary financial superiority. This point, already known from the argument for the protection of infant industries, reappears here as a possible support for incumbent managers, supposedly just about to succeed, against financially stronger raiders of lower potential EC.

Although this failure may be serious, it should not be overestimated. After all, it is also quite possible that some raiders might be better learners than the incumbent managers, who might not be about to succeed, but only say so. In general, the task of distinguishing true good learners from eloquent poor learners requires much of relevant EC, which again 
cannot be efficiently allocated without some evolutionary process involving both selection and learning. Of course, this is precisely the kind of EC in which the capital owners should excell, in order to be able to recognize, appoint, and/or invest in the managers who are the true good learners. But as no one is guaranteed to have enough of this EC either, no known alternative is superior to the double selection by the market for corporate control.

The other Schumpeterian fallure I wish to consider is excessive growth of firms. In the question of how large a firm should be allowed to grow, evolutionary reasoning can discover a delicate trade-off between economies of scale and conditions of evolution. This mitigates the modern "hospitable" view - as advocated in particular by Villiamson (1975) and Baumol et al. (1982) - that even a pery large firm can be socially efficient. To be sure, this view has also been advocated here, but with the important qualification that the firm must also possess sufficiently high EC. It is as the means to find and keep such high EC that an evolutionary process, providing for many trials and strict elimination of errors, has been found necessary. The trade-off stems from the fact that the presence of incrasingly large firms is likely to damage this process. As they are likely to dampen new trials and make the process lenient to their own errors, their efficlency becomes increasingly unlikely.

Even if difficult to determine with any prectsion, it is possible to assume an optimal trade-off between the economies of scale which an efficient large firm can realize - provided it is and remains efficient! and the damages to S-evolution which it is likely to cause. The question is then, how to shape the market for corporate control, in order to prevent firms from growing too far over such an optimum - e.g., by acquiring too many of their competitors. The search for suitable institutional rules 
seems to lead at least partly back to the old "inhospitable" view of the U.S. antitrust legislation that bigness is a threat to efficiency. The important difference is, however, that the main threat is now seen not in monopolistic pricing, but in the damages caused to the future S-evolution.

Yet the cause of the market for corporate control is again strengthened, rather than weakened. Even if it is recognized that the growth of firms over a certain limit should be institutionally constrained, the presence of this market pushes the limit higher than it would otherwise be. The reason is that the possibility of takeovers - be it realized or not - exerts an extra selective pressure on firms, in addition to the pressure exerted by their product markets. For instance, consider a product market with high costs of entry and exit ("low contestability"), which relieves a large firm of much of the latter pressure. If the competition for its control is open, however, increasing the probability of a takeover with decreasing performance, the loss of efficiency and innovativeness from which the firm might suffer will likely be alleviated. As a result, the tradeoff is made less severe: firms may be allowed to grow larger and/or the damages to the S-evolution may be kept smaller. 


\section{Dotes}

* The financial support of the Marianne and Marcus Vallenberg Foundation and the Danish Research Academy is gratefully acknowledged, as well as the hospitality of the Copenhagen School of Economics and Business Administration, where the first draft of this paper was written. I thank Kenneth Arrow, Kenneth Burdett, Richard Day, Gunnar Eliasson, Ove Granstrand, Henry Manne, Tony Marino, Roy Radner, F.M. Scherer, Clas Whlborg, and an anonymous referee for valuable comments on earlier drafts; none of them is responsible for the remaining errors, nor for my conclusions.

1. Although both evolutionary and comparative economics are the subject of a rapidly growing literature, they have little referred to each other. Even Schumpeter (1942), who discusses both capitalism and socialism, is evolutionary only about the former; he never applies his analysis of how structures are created and destroyed to socialism. As a consequence, nirvana fallacies are frequent whenever an evolutionary economist tries to draw policy conclusions.

2. As most economists are used to study only communicable information ("data"), it may be useful to emphasize that the term "information" has a broader meaning. In the natural sciences, information is, roughly, whatever contributes to guiding choices, regardless of whether it can be communicated or not. It is in such a broad meaning that the hardware of a computer, the structure of a brain, and the genes that have guided the formation and the development of this structure can be said to contain information. It is also in such a broad meaning that economic competence is regarded here as a kind of information.

3. In one-agent decision problems, it is perhaps possible to concede to the defenders of the optimization postulate that limited BC can be viewed 
as an additional resource constraint under which an agent still optimizes i.e. does his best under the constraint of his EC, however limited this might be. In multi-agent organizations, however, this view is definitely of no use. The reason is that resource connstraints must be there subject to inter-agent exchanges. Because an agent cannot convey his EC to another agent, this is precisely what EC-constraints cannot be. EC must thus be regarded as intrinsic to agents' behaviors, limiting their optimization abilities. If one still wanted to speak of optimization, it would be necessary to admit that each agent has his own idiosyncratic way to optimize, doing only his best, more or less remote from the best. To admit such a multitude of "optimizing" behaviors is to make the optimization postulate useless, indeed.

4. A recent analysis of this point in a different context will be found in Day and Pingle (1989),

5. Much of this paradox is due to the problem of self-reference. For a non-specialist in mathematical logic, Hofstadter (1979) is probably the best and most inspiring reading.

6. The present discussion is limited to the effects of institutional rules and regimes, assumed to be respected by the agents, while abstracting from the means - such as cultural conditioning and/or law enforcement - by which the agents' respect is obtained.

7. There is an instructive formal analogy between the couple 'regimestructure' of an organization and the couple 'genotype-phenotype' of a living organism. The analogy is also valid for the corresponding types of evolution. Two types can thus be distinguished: R-evolution - e.g., as studied by Hayek (1967, 1973) - comparable to the evolution of genotypes, or phylogeny; and S-evolution under a given $R$ - e.g., as studied by Schumpeter (1942) for capitalism - comparable to the evolution of a 
phenotype for a given genotype, or ontogeny. One limit of the analogy is, of course, that phylogeny is much slower than ontogeny, whereas regimes and structures may evolve at comparable speeds.

8. Another interesting difference is that unlike computer components, human agents are able to learn, and thus adapt themselves to, or be conditioned by, their tasks within organizations. But this difference should not be overestimated. Once it is clear that people are not infinitely malleable, but that all their learning is constrained by some initially given learning (including meta-learning) competence, this difference turns out to be smaller than it might seem. Whether individuals form organizations or vice versa, which has confused so many social scientists, can then clearly be decided. It is from individuals that their two-way relationship with organizations must begin to unfold, and it is their initially given learning competence that determines the limits to which they can be conditioned, in a feedback fashion, by their organizations. And although the two-way relationship may cause both the organizations and the individuals to evolve in a complex path-dependent fashion, the individuals' learning constraints are clearly basic.

9. Other theories which might be related to the present topic include agency theory and transaction costs theory. But these theories deal with economic organizations as they are, or should be, and not with how such organization form and evolve.

10. At a more abstract level - in the context of what may be denoted as $R-$ evolution, rather than the presently examined S-evolution - the study of self-organization in economic literature has been ploneered by Hayek (1967, 1973), in his discussions of spontaneous social orders.

11. According to modern neurophysiology, much of human learning reposes on structural changes within brains, involving changes of interconnections 
among neurons. This suggests that assoclative actions play a more general role in the formation and evolution of multilevel structures than what the above discussion implies.

12. As Eliasson and Ysander (1983) point out, some of such errors have been made consciously for short-term political reasons. But the part due to inadequate EC, causing the real outcomes to be far from those intended and expected by the politicians, is nevertheless important.

13. With emphasis on informational obstacles, the first answer was inttially stated by von Mises (1920) and Hayek (1935) and recently surveyed and developed by Lavoie (1985). The motivational obstacles were added above all by public choice theory, pioneered by Buchanan and Tollison (1972). The second answer was first outlined by Taylor (1929) and Lange (1936-7), and later rigorously elaborated within the framework of neoclassical economics by Arrow, Hurwicz, Malinvaud, and Heal, among others (for a survey, see Heal 1972). Within this framework, both kinds of obstacles are elegantly overcome - the former by informational decentralization, and the latter by ingenious incentive-compatible arrangements (see, e.g., Loeb and Magat 1978).

14. That all proofs of the existence of efficient soclalist planning require perfectly optimizing producers deserves emphasis. This suggests that, ironically enough, Friedman (1953) subverts his favorite cause of capitalist market economy by defending the optimization postulate as a generally ralid methodological principle, rather than an approximation of a particular result of market selection. What may well be the greatest specific advatage of capitalist markets and the greates obstacle to socialist planning is thus obscured; in particular, the market for corporate control then appears entirely useless. For empirical observations of how scarce and unequally distributed $E C$ may be, and how inefficient its allocation may 
become when market selection is put out of work, Czechoslovakia as a soctalist country with old industrial traditions appears ideal. Although a systematic inquiry is methodologically difflcult and politically unfeasible, there is a wide-spread conviction that to allow economic incompetence to prosper even at the level of the most important organizational, managerial, and investment decisions was by far the greatest economic disaster caused by socialisation. 


\section{References}

Alchian, A.A. (1950), "Uncertainty, evolution and economic theory," Journal of Political Economy 58, 211-222.

Baumol, W.J., J.C. Panzar, and R.D. Willig (1982), Contestable Yarkets and the Theory of Industry Structure, San Diego: Harcourt Brace Jovanovich. Commons, J.R. (1929), The Legal Eoundations of Capitalism ...

Day R.H. and ... Pingle (1989) ...

Demsetz, H. (1969), "Information and efficiency: another viewpoint," The Journal of Law and Economics 12, 1-22.

Eliasson, G. (1985), The Eirm and Einancial Markets in the Swedish Microto-Kacro Model = Theory Kodel, and Verification, The Industrial Institutut for Economic and Social Research, Stockholm.

Eliasson, G. and B.-C. Ysander (1983), "Sweden: problems of maintaining efficiency under political pressure," in B. Hindley, ed., State Investment Companies in Vestern Europe: Bicking Vinners or Backing Losers?, London: Trade Policy Research Center.

Friedman, M. (1953), Essays in Positive Economics, Chicago: University of Chicago press.

Hayek, F.A., ed., (1935), Collectivist Economic Planning, London: Routledge \& Kegan Paul.

Hayek, F.A. (1967), "Iotes on the evolution of systems of rules of conduct," in F.A. Hayek, Studies in Philosophy, Polltics, and Economics, London: Routledge \& Kegan Paul. Hayek, F.A. (1973), Law Legislation, and Liberty, London: Routledge Kegan Paul. 
Heal, G. (1973), The Theory of Economic Blanning, Amsterdam, Hew York, Oxford: Iorth-Bolland.

Heiner, R.A. (1983), "The origin of predictable behavior," American Economic Review $83,560-595$.

Hofstadter, D.R. (1979), Gödel, Escher, Bach: An Eternal Golden Braid, New York: Basic Books.

Hurwicz, L. (1971), "Centralization and Decentralization in Economic Processes", in A. Eckstein, ed., Comparison of Economic Systems, The University of California Press.

Jensen, M.C. (1988), "Takeovers: their causes and consequences," The Journal of Economic Perspectives 2, 21-48.

Lange, 0. (1936-7), "On the economic theory of socialism," Review of Economic Studies 4, Nos. 1 and 2. Reprinted in Lippincott, B., ed., (1964) On the Economic Theory of Socialism, New York: McGraw-Hill Paperback.

Lavoie, D. (1985), Lational Economic Planning: What is Left?, Cambridge, Mass.: Ballinger.

Loeb, M. and V.A. Kagat (1978), "Success indicators in the Soviet Union: the problem of incentives and efficient allocation," American Economic Review 68, 173-181.

Lucas, R.E. Ir. (1978), "On the size distribution of business firms," Bell Journal of Economics 2, 508-23.

Manne, H.G. (1965), "Mergers and the market for corporate control," Journal of Political Economy 73, 110-20.

Marris, R. (1963), "A model of the 'managerial' enterprise," Quarterly Journal of Economics 77, 185-209.

Marris, R. and D.C. Xueller (1980), "The corporation, competition, and the Invisible Hand," The Journal of Economic Literature 18, 32-63. 
von Mises, L. (1920), "Economic calculation in the soctalist commonwealth," Archive für Sozialwissenschaften, reprinted in F.A. Hayek, ed., (1935), Collectivist Economic Planning, London: Routledge \& Kegan Paul.

Pelikan, P. (1985), "Private Enterprise v. Government Control: An Organizationally Dynamic Comparison," Vorking Paper 137, The Industrial Institutut for Economic and Social Research, Stockholm.

Pelikan, P. (1988), "Schumpeterian efficiency of different economic systems," presented at the meeting of the J.A. Schumpeter Society in Siena, May 1988, and Working Paper 194, The Industrial Institutut for Economic and Social Research, Stockholm.

Polanyi, M. (1962), Personal Knowledge: Iowards a Post-Critical Philosophy, New York: Harper Torchbooks.

Radner, R. (1986), "The internal economy of large firms," Economic Journal 96. Conference Papers 1-22.

Scherer, F.M. (1988), "Corporate takeovers: the efficiency argument," The Journal of Economic Perspectives 2, 69-82.

Schumpeter, J.A. (1942), Capdtalism. Socialism, and Democracy, New York: Harper and Row.

Shleifer A. and R.W. Vishny (1988), "Value maximization and the acquisition process," The Journal of Economic Perspectives 2, 7-20.

Simon, H.A. (1955), "A behavioral model of rational choice," Quarterly Journal of Economics 69: 99-118.

Simon, H.A. (1969), The Sciences of the Artiflcial, Cambridge, Mass.: MIT Press.

Simon, H.A. (1978), "Rationality as process and as product of thought," Americal Economic Review 68, 1-16.

Stiglitz, J.E. (1984), "Information and economic perspective," Economic Journal 24, 21-41. 
Stiglitz, J.E. (1987), "Learning to learn, localized learning, and technological progress," in P. Dasgupta and P. Stoneman, eds., Economic Policy and Technological Performance, Cambridge: Cambridge Univesity Press.

Taylor, F.M. (1929), "The guidance of production in a socialist state," American Economic Review 12, 1-8. Reprinted in Lippincott, B., ed., (1964) On the Economic Theory of Socialism, New York: McGraw-Hill Paperback.

Valdman, K. (1984), "Job assignement, signalling, and efficiency," Rand Journal of Economics 15, 255-67.

Williamson, O.E. (1975), Markets and Hierarchies: Analysis and Antitrust Implications, New York: Free Press.

Williamson, O.E. (1985), The Economic Institutions of Capitalism, New York and London: The Free Press.

Winter, S.G. (1971), "Satisficing, Selection, and the Innovative Remnant," Quarterly Journal of Economics 85, 237-261. 